\title{
El rol secundario del agresor en las noticias televisivas sobre violencia machista
}

\section{The secondary role of the aggressor in television news on gender violence}

\author{
Susana Moreno Pachón. Universidad Camilo José Cela (smoreno@ucjc.edu) \\ María del Carmen García Galera. Universidad Rey Juan Carlos (carmen.garcia@urjc.es)
}

Recibido: 28/08/16 - Aceptado: 05/10/16

\section{Resumen:}

La violencia machista es la más grande historia de desamor de la humanidad. Mitos que culpabilizan a la mujer de la expulsión del paraíso, la ablación, la violencia en el hogar, la violación como arma de guerra o las lapidaciones, reflejan circunstancias en las que las mujeres son víctimas indefensas. En el contexto español, parece que la influencia de los medios de comunicación no logra penetrar a fondo en la conciencia social contra esta lacra. El objetivo del presente estudio es determinar qué efectos tienen los contenidos informativos televisivos sobre violencia de género y, en concreto, cómo retratan al sujeto de la agresión en el relato audiovisual. El estudio recoge una metodología cuantitativa -a partir del análisis de los 3660 informativos anuales de las cinco cadenas nacionales españolas-, y cualitativa, a través de entrevistas en profundidad a personas que trabajan de cerca con este problema social.

Palabras clave:

Mujer, violencia machista, informativos, televisión, agresor

Abstract:

Male violence against women is humankind's most notable example of lack of affection. Myths that have blamed women for the expulsion from Paradise, genital mutilation, domestic violence, the use of sexual violence as weapon of war, or women being stoned, are all reflections of the circumstances in which women are defenseless victims. In Spain, it appears that the influence of the media has failed to penetrate deeply into the social conscience, something that is needed in order to tackle this scourge. The aim of this research is to determine the influence that news-related television contents have had upon gender violence and, more specifically, the way in which the aggressor is depicted in audiovisual storytelling. This study encompasses both a quantitative methodology - which has been gathered from the analysis of the 3660 yearly news editions from five national Spanish networks- and a qualitative methodology as well, through the use of comprehensive interviews of the individuals who closely work with this social problem.

Keywords:

Woman, gender violence, news programs, aggressor 


\section{Introducción}

En el fenómeno de los malos tratos hacia las mujeres en el contexto familiar, se pueden distinguir dos actores principales: el agresor y su víctima. La acción del primero genera una lacra que se ha cobrado (a fecha de 3 de octubre de 2016) un total de 859 muertes desde el año 2003, fecha en la que el Ministerio de Sanidad y Servicios Sociales comenzó a recoger estadísticas de manera oficial (http://estadisticasviolenciagenero.msssi.gob.es/).

Gallego (2003) apuntaba a que la histórica invisibilidad de los malos tratos con la aquiescencia de la sociedad se debía a la alianza cómplice de los diferentes agentes implicados: 1) La policía, que atribuía el problema a la normal relación entre hombres y mujeres, restando importancia a las denuncias; 2) Los médicos, que no indagaban en el origen de las agresiones ni las denunciaban salvo en caso de muerte; 3) Los jueces, que solo intervenían en última instancia e imponían penas ligeras; y 4) Los medios de comunicación que tipificaban como suceso estos crímenes y no cuestionaban la versión policial o judicial.

Algo ha cambiado en tanto que, en la última década, se han redoblado y aunado los esfuerzos desde todos estos ámbitos mencionados e implicados en la violencia machista para tratar de visibilizar esta herida social. Uno de los avances más significativos a nivel legislativo fue la redacción de la Ley Orgánica 1/2004 de 28 de diciembre, de Medidas de Protección Integral Contra la Violencia de Género, que ha servido de inspiración para otras legislaciones europeas.

Pero, además, tal y como confirman Varona y Gabarrón (2015) en su estudio, en los últimos años la violencia de género se ha consolidado como un tema recurrente dentro de la agenda política española. Convendría añadir que también en la social. En esta misma investigación, estos autores plantean que la percepción de la violencia contra la mujer como un problema público depende fundamentalmente de la intensidad de su cobertura mediática y no de otras variables. Por lo tanto, no se trata solo de que se dé a conocer a través de los medios de comunicación, sino de cómo se informa o sobre qué contenidos se pone un mayor énfasis.

Herrera y Expósito (2009) comprobaron que la percepción que la opinión pública tiene de la violencia de género está muy vinculada al tratamiento que esta recibe por parte de los medios de comunicación. En su estudio, observaron que la forma de dar la noticia sobre violencia contra la mujer condicionaba la posición del grupo, de manera que cuando la información se centraba en el agresor, el grupo interpretaba los hechos en torno a él; cuando lo hacía sobre la víctima, era ella la que ocupaba el centro de los razonamientos; y cuando la información se daba con carácter neutro, se recurrían a elementos que la cultura ha puesto alrededor de esa violencia, como por ejemplo, los celos o los problemas económicos de la pareja. Así pues, a raíz de estos resultados, se pudo concluir que el modo de presentación de las noticias constituye uno de los factores más influyentes en la percepción individual de la violencia de género y en la aceptación de la misma. 
Por ello, el rol que el agresor ocupe en la información sobre violencia de género parece tener un papel importante si se quiere concienciar a la sociedad sobre esta lacra social. En este contexto, conviene aclarar, en primer lugar, algunos conceptos o ideas prefijadas sobre la agresividad que aparece en los medios de comunicación con relativa frecuencia. Así, por ejemplo, la agresividad no es exclusiva de un determinado perfil de personas, aunque hay algunos estudios clásicos, como el de Conger y Miller (1966) que recogen que entre los hombres violentos se encuentra un porcentaje más elevado de psicópatas y neuróticos que entre la población normal. Pero este hecho no es determinante para concluir que el hombre que ejerce violencia sobre su pareja sufre necesariamente de algún trastorno mental, como algunos medios parecen empeñados en justificar.

La descripción que hace López (2004) de las características del agresor, recalca que el hombre violento tampoco es exclusivo de una determinada clase social y que puede existir en cualquier ciudad y lugar. Considera asimismo, que aunque no es posible generalizar sobre las características personales de aquellos que provocan este tipo de actuaciones, existen ciertas peculiaridades, vivencias y situaciones específicas comunes a la mayoría de ellos. Así, un gran porcentaje de maltratadores ha sido, por ejemplo, víctima o testigo de malos tratos, adoptando este comportamiento como una forma normal de relacionarse. Lo han experimentado como sistema de poder, aprendiendo que ejerciéndolo en el hogar obtienen la máxima autoridad y consiguen lo que quieren. Asimismo, suelen tener una imagen muy negativa de sí mismos, provocando esto una baja autoestima, sintiéndose por esto fracasados como persona, y consecuentemente actuando de forma amenazante y omnipotente y reforzándose así con cada acto de violencia.

Para Espada y Torres (1996), el hombre violento es el resultado de un sistema social que ofrece los ingredientes para alimentar esta forma de actuar; aspira a ejercer un poder y control absolutos sobre su pareja en lo que hace y en sus pensamientos y sentimientos más íntimos; considera a su pareja como una posesión que tiene derecho a controlar en todos los aspectos de su vida.

En esta misma línea, el Informe del Defensor del Pueblo (2008) sobre violencia contra la mujer asegura que el agresor o el hombre que emplea la violencia no pertenece a una determinada clase social y no está enfermo sino que reproduce actitudes estereotipadas y cree que, por el hecho de ser hombre, ha de ejercer el poder dentro de la familia.

Este mismo informe reconoce que la conducta violenta está provocada por factores genéticos, sociales, culturales y psicológicos, aunque los factores biológicos — hormonas, disfunción neurofisiológica o herencia — no actúan de forma específica como causantes de la violencia. Asimismo, se citan varios estudios llevados a cabo en Estados Unidos, Inglaterra, Escocia, Francia y Holanda para determinar que la violencia es un comportamiento aprendido ya que el $81 \%$ de los hombres maltratadores fueron testigos o víctimas de malos tratos en su niñez.

En este sentido, los expertos apuntan a los principios culturales, costumbres sociales y normas religiosas, como factores determinantes para ejercer y justificar la violencia contra mujeres y niños. "En nuestra cultura, y desde hace muchos si- 
glos, a los padres se les ha adjudicado una autoridad incuestionable sobre su descendencia, y al hombre la misma autoridad y poder sobre la mujer. Estas ideas irracionales se han transmitido y aprendido de generación en generación" (Oficina del Defensor del Pueblo, 2008, p.103).

Ferrer y Bosch (2005) ofrecen, a partir de un análisis de conglomerados efectuado con datos aportados por mujeres víctimas de malos tratos atendidas en diversos centros, una clasificación de cuatro tipos de agresores (con una distribución porcentual muy homogénea: 1) un grupo de maltratadores jóvenes (menos de 40 años), con estudios básicos, problemas de consumo de alcohol, sin problemas psicopatológicos, con antecedentes de violencia familiar, celosos y agresivos solo en el ámbito familiar; 2) un segundo grupo similar al primero pero de más edad y sin antecedentes previos de malos tratos en su familia; 3) un tercero de agresores de edad intermedia, con buen nivel de estudios, sin antecedentes violentos familiares ni problemas psicopatológicos ni de consumo de sustancias, celosos y violentos solo con su familia; y 4) un cuarto grupo de maltratadores jóvenes, con un nivel educativo básico, con problemas de consumo con el alcohol pero no con otras drogas, celosos, sin trastornos psicopatológicos y violentos solo con su familia.

Con posterioridad, Expósito y Ruíz (2009) establecen una tipología de dos clases de maltratadores: los que se caracterizan por una personalidad en general compulsivo-dependiente y los que evidencian rasgos antisociales, paranoides, narcisistas y agresivos.

Otro rasgo que distingue al maltratador de otro tipo de delincuente, es el hecho de plantearse el suicidio o incluso consumarlo, después de dar muerte a su víctima. Este tipo de reacción, según Fernández Teruelo (2011), se aleja de lo característico, incluso en la delincuencia violenta extrema (con resultados mortales), lo que pone de relieve la extraordinaria singularidad de los homicidios o asesinatos de género y la necesidad de acordar pautas de actuación y tratamiento distintas a las que se emplean para el resto de la criminalidad violenta. Dubugras y Guevara (2007) defienden que una decisión de homicidio no da lugar a una posterior decisión de suicidio sino que ambas conductas están concebidas como un plan común, sin improvisación de por medio. Ambas autoras sostienen que el perfil del homicida-suicida se aproxima más al perfil del suicida que al del homicida. Montero Gómez, en el periódico El Correo, afirma que la dominación es el sustento de la violencia machista pero también del posterior suicidio del victimario.

"En violencias sistemáticas, el agresor machista ha construido su universo vital prácticamente alrededor de la dominación traumática de una mujer. Cuando es prolongado, el sometimiento de otro ser humano acaba convirtiéndose en el centro de la vida del agresor, es el referente que le otorga significado primordial a su existencia. Cuando desaparece ese centro, la vida pierde sentido para el torturador" (El Correo, 2006)

En España, tal y como muestra el Gráfico 1 -referida a los últimos cinco años- y con datos extraídos del Consejo General del Poder Judicial, prácticamente uno de cada tres agresores intenta suicidarse o lo consigue, tras cometer el crimen. Si bien 
son datos que no pueden compararse con otros referidos a la relación entre homicidios y posterior suicidio -ya que no hay estadísticas completas que recojan este fenómeno- sí se puede apreciar que en el caso de los feminicidios el número de intentos o de suicidios consumados es alto, y se ha incrementado con los años, lo que actualiza y refuerza el planteamiento de Dubugras y Guevara (2007).

Gráfico 1. Suicidio del agresor tras consumar su homicidio

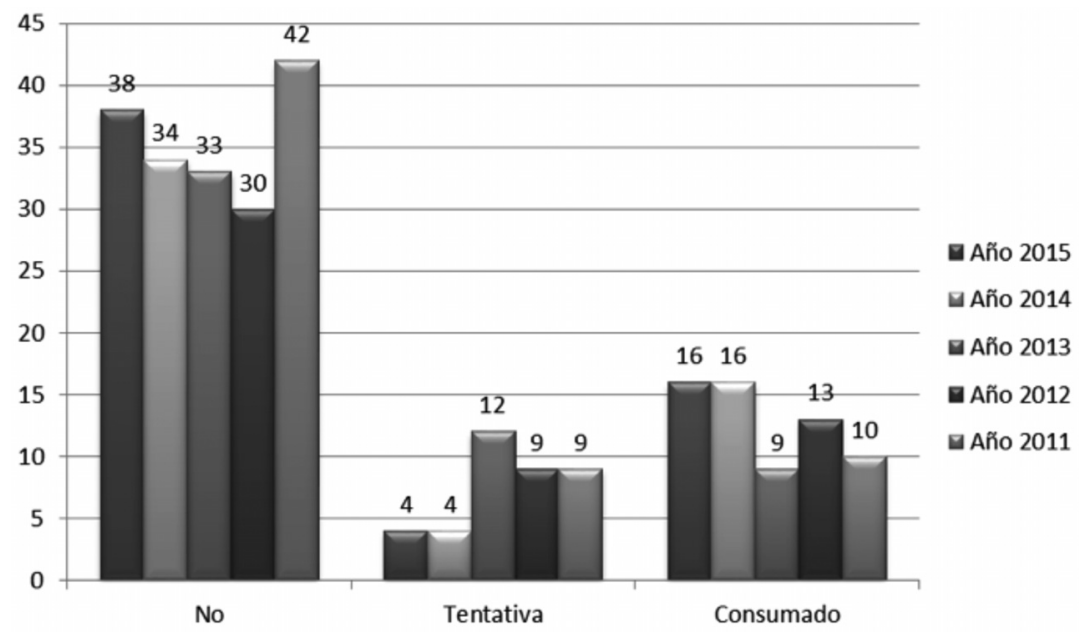

Fuente: Consejo General del Poder Judicial. Elaboración propia

Sobre las causas del suicidio tras el feminicidio, Fernández Teruelo (2011) afirma que la teoría de que el agresor se suicida tras matar a su pareja o expareja porque no puede soportar el rechazo social que provoca sus actos, es errónea. Y esgrime numerosas experiencias y estudios con agresores de género en centros penitenciarios para afirmar que el hombre que acaba con la vida de una mujer con la que mantuvo una relación sentimental, es escasamente permeable a los estímulos externos. Más bien responde a un sujeto victimista que está convencido de lo correcto de su actuación y de lo 'merecido' del castigo a su pareja por haberse desviado de las obligaciones para con él establecidas.

"Una parte importante de los agresores que llegan al feminicidio han conformado su esquema vital sobre la base de una relación de dominio absoluto de su pareja en la que se usa la violencia para reafirmar ese control. La pérdida brusca de ese modelo que consideraba blindado acaba con la eliminación física de la mujer y a veces con la muerte del agresor al entender que su existencia no tiene sentido sin ese modelo de control” (Fernández Teruelo, 2011, p.14).

Por tanto, la principal diferencia entre el agresor que mata a su pareja o su expareja y luego no acaba con su propia vida del que sí lo hace es, al entender de los expertos, el mayor o menor arraigo de ese modelo. En uno y otro caso el momento más 
peligroso es la ruptura o el anuncio de la misma: El riesgo de feminicidio se incrementa nueve veces si a la relación basada en el abuso físico se le añade la separación o amenaza de ruptura por parte de la mujer, según Campbell et al. (2003).

No obstante, a pesar de estos intentos de clasificar e intentar hacer un perfil del agresor en los contextos de violencia machista, Álvarez-Dardet, Pérez y Lorence (2013), después de una revisión muy detallada y minuciosa de los principales estudios realizados hasta el momento al respecto, llegan a concluir que no parece que se pueda hablar de un perfil homogéneo de hombres que maltratan a sus parejas. Esta situación, probablemente, sea un problema añadido a la hora de informar sobre esta lacra a la sociedad a través de los medios de comunicación, y más concretamente de la televisión, ya que tanto la figura del agresor como la de la víctima continúan apareciendo rodeadas de algunos tópicos relacionados con la procedencia o estatus social y cultural de ambos protagonistas, o las dependencias, adicciones o los trastornos físicos y psicológicos del maltratador. Estos argumentos, además, se presentan descontextualizados y parecen justificar la acción del agresor, de manera que la sociedad pueda encontrar una razón para tanta barbarie.

Para Comas (2015), la violencia practicada por el hombre sobre la mujer en el contexto familiar o doméstico ha sido ampliamente tolerada y considerada como normal. Uno de los objetivos del feminismo ha sido hacer visible esta violencia "escondida" que tenía y tiene lugar en los hogares. La razón que explica este ocultamiento está en que ha sido culturalmente e incluso legalmente aceptado y considerado como un asunto privado. El cambio, según esta autora, de la opacidad a la transparencia, o de ser algo privado a ser un problema social es el resultado de una compleja interacción entre movimientos sociales, políticos, ciudadanos y los propios medios de comunicación.

Desde este artículo, se trata de hacer una descripción de cómo los medios de comunicación, la televisión y sus informativos en concreto, difunden noticias sobre violencia de género en las que los agresores son desplazados a un papel secundario e incluso a veces inexistente dentro del discurso. Esta difuminación del agresor podría tener un cierto efecto imitación sobre aquellos otros agresores que, lo que ven reflejado en la televisión, es lo que a ellos les gustaría experimentar sobre sus parejas (la violencia) y no las consecuencias sobre su persona -detención, condena social y legal-.

Vives-Cases, Torrubiano y Álvarez-Dardet (2009), tras analizar 3733 noticias televisivas sobre violencia machista y 340 homicidios, concluyeron que las informaciones sobre asesinatos a mujeres aumentaban la posibilidad de un nuevo homicidio entre un 32 y un 42 por ciento, mientras que la informaciones centradas en las leyes o declaraciones de expertos, podrían generar un efecto contrario.

En esta misma línea, el estudio de la Delegación del Gobierno para la Violencia de Género realizado un año después -y centrado en el medio televisivo- concluyó que, a semejanza del suicidio, en la violencia machista el efecto imitación será mayor cuando las noticias contribuyan más a la identificación entre el homicida y un agresor potencial, bien por presentarlo como parte de lo inexplicable o introduciendo justificaciones como trastornos mentales. 
Por lo que respecta a la opinión de los propios profesionales de los medios de comunicación, la encuesta del Centro Reina Sofía y el Ministerio de Sanidad, Política Social e Igualdad realizada entre 945 periodistas (vía on line) y 1200 ciudadanos (vía entrevista telefónica) (http://igualdade.xunta.gal/sites/default/files/files/documentos/como_informar_violencia_parella.pdf), pone de manifiesto que el 55,5 por ciento de los periodistas cree que la forma de dar la información sobre violencia contra la mujer puede contribuir a que se produzcan casos similares, mientras que el 61,5 por ciento de los ciudadanos está convencido de que a veces la manera en que los medios de comunicación cuentan la información puede conducir a que se produzcan casos similares principalmente porque estiman que se facilitan ideas a otros potenciales agresores.

Según Eduardo Castro (2016), miembro del Consejo Audiovisual de Andalucía, recae en los periodistas y en los medios de comunicación una cierta responsabilidad a la hora de luchar contra la violencia machista, pues constituyen la primera fuente de información sobre este problema social para el 95 \% de la población. Sin embargo, a pesar de que el periodismo ha situado desde hace años este asunto en la agenda pública, los informes del Consejo constatan que con frecuencia este tipo de sucesos están teñidos de sensacionalismo o descontextualizados (http://fape.es/el-consejo-audiovisual-deandalucia-presenta-en-almeria-su-guia-para-informar-sobre-la-violencia-de-genero/?platform=hootsuite)

Comas (2015), en su estudio, plantea también que a partir de la investigación llevada a cabo en diferentes países, los medios enmarcan la violencia de género contra la mujer como un asunto individual, en lugar de como un problema social. No así el caso de España. Según esta autora, la violencia contra la mujer ha adquirido su propia identidad como un problema social y se presenta en los medios de comunicación vinculados a contextos políticos, policiales judiciales y sociales, con las acciones que se desarrollan desde todos estos ámbitos con el fin de eliminar el problema.

\section{Métodos}

Una vez descrita algunas de las características del agresor de violencia de género o violencia machista, el objetivo general del estudio que aquí se presenta es identificar las pautas de comportamiento de los medios de comunicación, en concreto, de los informativos de televisión a la hora de informar acerca de este tipo de violencia. El objetivo específico pasa, en primer lugar, por conocer cómo informan las cinco cadenas nacionales de televisión sobre estos sucesos y, en segundo lugar, qué rol tiene el agresor en el relato que llega a la audiencia. La hipótesis pues, viene a resaltar que a pesar del papel que el agresor tiene en el acto violento contra la mujer, los medios de comunicación le relegan a un rol secundario, y justifican ocasionalmente su agresión basándose en estereotipos (trastornos psicológicos, celos...)

En cuanto a las técnicas de investigación utilizadas, se ha recurrido a la triangulación metodológica, es decir, a la combinación de técnicas cualitativas y cuantitativas de investigación lo que permite comprender en su totalidad el objeto de estudio y se refuerza la validez de los resultados (García y Berganza, 2005). Así, con el fin de obtener resultados válidos y 
fiables sobre el objeto de estudio, se utilizaron la técnica cualitativa de la entrevista en profundidad y la técnica cuantitativa del análisis de contenido.

Respecto a la entrevista, se llevó a cabo entre expertos, ya que era necesaria la visión de aquellas personas que tienen, o bien un punto de vista global sobre todo el proceso que conlleva la violencia machista, o bien son parte decisora sobre lo que se emite en televisión. Por todo ello, la muestra de expertos incluyó a los tres máximos responsables de los servicios informativos de las cinco cadenas analizadas, ya que algunas de ellas pertenecen al mismo grupo mediático; tres funcionarios (policía, juez y fiscal) especializados en violencia machista y su procesamiento; y un experto en violencia machista, máximo responsable de uno de los organismos estatales con mayor reconocimiento en este campo, el Observatorio contra la Violencia Doméstica y de Género.

El análisis de contenido se consideró la metodología cuantitativa más adecuada en este contexto, que nos permitiría encontrar la respuesta a cómo los informativos de televisión abordan los sucesos sobre violencia de género y qué papel juegan los agresores en este discurso. El universo analizado fueron los informativos de las cadenas nacionales españolas, a saber, TVE1, Antena 3, Cuatro, Tele 5 y La Sexta. La muestra recogida fueron los informativos de lunes a domingo y en las ediciones de mañana y tarde, de todo el año 2012, año seleccionado por ser el que menor número de muertes por violencia contra la mujer registró desde 2003 (fecha en la que el Ministerio de Sanidad empezó el registro oficial). Es decir, que se analizó el cien por cien del universo.

Todo ello ha constituido el análisis de 3660 informativos, que emitieron un total de 283 noticias relacionadas con la violencia machista, de las cuales 198 informaron del hecho puntual de la muerte de alguna de las 52 mujeres que fallecieron asesinadas a manos de sus parejas o exparejas el año objeto de estudio. Así, la noticia principal analizada ha sido casos de violencia machista con resultado de muerte. Las 85 informaciones restantes las denominamos noticias complementarias ya que no se refieren al hecho concreto de una muerte por violencia machista sino a nuevas campañas del gobierno, efectos de los recortes en las medidas de prevención, Día Internacional contra la Violencia de Género, detenciones de presuntos agresores o celebraciones de juicios, entre otros.

\section{Resultados}

Uno de los debates más intensos en las redacciones de las televisiones nacionales gira sobre la figura del agresor y la emisión de su imagen. Por un lado, hay expertos que reclaman establecer el límite entre la criminalización y la exposición pública de alguien que, a priori, goza de la presunción de inocencia, para que no sufra la denominada "pena del telediario" (es condenado por la opinión pública sin que se haya celebrado siquiera el juicio). En este contexto, la Ley Orgánica 1/1982, de 5 de mayo, en el artículo primero, tres, reconoce que el derecho al honor, a la intimidad personal y familiar y a la propia imagen es irrenunciable, inalienable e imprescriptible. 
Sin embargo, cada vez son más los expertos, periodistas y colectivos sociales que consideran que a los agresores hay que conocerlos por su fotografía, su nombre y su apellido para cambiar de una vez por todas el mensaje que se pretende hacer llegar a la sociedad y que es el de que existe una persona que ha cometido un delito grave y que ha de responder por ello ante la justicia. Así, por ejemplo, el manual de estilo de RTVE dice explícitamente respecto a la identificación de autores de actos delictivos que "es nuestra obligación identificar suficientemente al presunto delincuente porque esos datos forman parte esencial del hecho sobre el que informamos" (http://manualdeestilo.rtve.es/cuestiones-sensibles/5-10delincuencia/5-10-3-identificacion-de-los-autores/ Consultado el: 4/04/16).

Para Bandrés (2011), si no hay una identificación visual del agresor, se diluye el concepto racional de culpabilidad y parece que la noticia es relatada como un género de ficción. En televisión raramente aparece el nombre y los apellidos del presunto agresor, pero sí se emiten fotografías de las víctimas y hasta se revela su nombre, edad o lugar de residencia, lo que, al parecer de Bandrés, supone un maltrato informativo a la dignidad de la víctima.

La encuesta a periodistas y ciudadanos del Centro Reina Sofía y el Ministerio de Sanidad, Política Social e Igualdad refleja opiniones contrarias entre periodistas y ciudadanos ya que un $88,7 \%$ de los profesionales de la comunicación opina que se debe hacer constar lo que ocurre con el presunto agresor tras cometer la agresión; en segundo lugar, si padece alguna psicopatología (71,2\%), y su edad (55,8\%). Además, un 62,3\% cree muy importante publicar si el presunto agresor se ha suicidado o al menos lo ha intentado, porque cree que esta circunstancia muestra el estado mental en que se encuentra. Frente a este dato, el $81,8 \%$ de los ciudadanos no considera relevante que se cuente si el presunto agresor se ha suicidado o lo ha intentado tras la agresión, porque consideran que lo importante en estos casos es la víctima.

\subsection{Imagen del agresor}

Por lo que respecta al análisis de las imágenes, las relacionadas con el presunto agresor escasearon en las noticias principales de los informativos ya que no existe acceso a ellas, salvo que la policía las pudiese facilitar, cosa que, hoy por hoy, no ocurre. Así, Telecinco y Cuatro fueron las que más veces emplearon este tipo de imágenes aun siendo porcentajes muy bajos (15,2\% y 12,3\%, respectivamente) y después La Sexta (10,3\%) y Televisión Española (7,5\%), mientras que Antena 3 no publicó una sola imagen de los agresores en ninguna de sus informaciones de todo el año (Tabla 2): 
Tabla 2. Uso de imágenes del agresor

\begin{tabular}{|c|c|c|c|c|c|c|}
\hline \multirow{2}{*}{} & \multirow{2}{*}{ TOTAL (\%) } & \multicolumn{5}{|c|}{ CADENAS } \\
\cline { 3 - 7 } & & TV1 & A3 & Cuatro & T5 & La Sexta \\
\hline Sí apareció & 9,9 & 7,53 & & 12,31 & 15,15 & 10,34 \\
\hline No apareció & 90,1 & 92,47 & 100,00 & 87,69 & 84,85 & 89,66 \\
\hline
\end{tabular}

Matriz de resultados del análisis de los informativos

Fuente: Elaboración propia

Las escasas escenas sobre el agresor a las que los medios de comunicación tienen acceso, le suelen mostrar con el rostro oculto en el momento de la detención o durante el juicio, o en planos alejados y con las manos esposadas ocultas. Estas imágenes suelen producirse varios días o semanas después de informar sobre el hecho puntual de la muerte (noticias principales), por lo que se emiten en las denominadas noticias complementarias, tal y como muestra la Tabla 3 :

Tabla 3. Uso de imágenes del agresor según noticia

\begin{tabular}{|l|c|c|c|}
\hline \multirow{2}{*}{ IMGAgresor } & \multirow{2}{*}{ TOTAL (\%) } & \multicolumn{2}{|c|}{ TIPO DE NOTICIA } \\
\cline { 3 - 4 } & & COMPLEMENTARIA & PRINCIPAL \\
\hline \multirow{2nnn}{*}{} & 9,9 & 27,7 & 4,6 \\
\hline
\end{tabular}

Matriz de resultados del análisis de los informativos

Fuente: Elaboración propia

Como se ha señalado anteriormente, la publicación de imágenes en la que aparezca el presunto agresor -ya sea en noticias principales o complementarias- es objeto de una intensa discusión entre la sociedad, los medios de comunicación y numerosos expertos. Los funcionarios entrevistados consideran que hay que proteger la presunción de inocencia pero son partidarios de que se muestre al agresor, aunque sea de espaldas. "Yo creo que este tipo de imágenes sí que ayudarían a proyectar el mensaje de otra manera (...) nos diría que esta persona va en este coche de policía porque va a responder por sus actos. Siempre respetando la presunción de inocencia, porque muchas veces se va buscando sacar el rostro" (Funcionario 1); "Hay que poner incluso su nombre, aunque por delante vaya la palabra presuntamente. Yo creo que ahí es donde hay que insistir (...) e incluso si son ya condenados, se les podría poner la foto. (...). Que todo el mundo reciba el mensaje de que si tú haces lo mismo que esta persona te van a caer 30 años de cárcel y sin ningún tipo de permiso" (Funcionario 2); "A un asesino hay que detenerle, juzgarle y enviarle a la cárcel, pero no exponerlo públicamente. Yo creo que no deberían publicarse imágenes del agresor porque no sé lo que queremos conseguir. ¿Queremos que la gente lo señale diciendo que es un asesino? (...). Esa persona tiene derecho a su honor y su intimidad por muy asesino que sea" (Funcionario 3 ). 
El experto en violencia de género considera que la emisión de la imagen de un agresor de violencia machista solo serviría para darle más publicidad y solo publicaría imágenes del autor de la agresión en el caso de obtener su consentimiento: "Creo que no habrá más repulsa contra los malos tratos por el hecho de publicar su imagen. Yo solo lo haría siempre que no afectase a su integridad personal, y con su consentimiento, pero creo que es más importante dar difusión a las sentencias condenatorias, (...) a la idea de que no hay impunidad para este tipo de delitos" (Experto en violencia de género).

Para los responsables de los medios televisivos, la emisión de unos planos en los que aparezca el agresor es complicada porque no están disponibles en el momento del relato de los hechos, y porque de existir esa imagen, el detenido sigue llevando la etiqueta de "presunto": "Los medios tratamos de no hacerle caso (...) porque en ocasiones el agresor se puede sentir hasta importante por salir en la tele (...) pero es verdad que esto requeriría un debate mucho más profundo. La sociedad tiene que entender que la persona que lo ha hecho va a cumplir condena en la cárcel, (...) que su vida se destroza. Probablemente hay que hacer más hincapié en ese tipo de datos, pero es complicado porque lo que normalmente narramos es el relato de los hechos" (Periodista 2); "Yo estoy más en la tesis de que no hay que prescindir de estas imágenes y que hay que subrayar en el discurso que estamos hablando de un presunto (...) También considero que hay una gran carencia de imágenes de las detenciones de los presuntos maltratadores y de los juicios, así como de información sobre el seguimiento de los casos" (Periodista 3).

\subsection{Declaraciones del agresor}

En la Tabla 4 que se adjunta a continuación, se señalan aquellas cadenas que se hicieron eco de las palabras del agresor, siendo Televisión Española y Antena 3 las que en menos ocasiones recogieron este tipo de declaraciones, frente a La Sexta, que lo hizo en un 10,3\% de las noticias, Telecinco en un 4,5\% y Cuatro en un 4,6\%. Parece pues, que al igual que ocurre con las imágenes, no hay declaraciones públicas del agresor. En las contadas ocasiones que se pueden escuchar, los acusados tratan de esgrimir más justificaciones que arrepentimiento por su acción criminal.

Por otra parte, la observación de los informativos como parte de la dinámica metodológica del estudio, ha permitido deducir que en la mayoría de los casos, los testimonios de los agresores han llegado a las redacciones de las cadenas a través de agencias de noticias ya que se han repetido las mismas declaraciones, en las mismas noticias, los mismos días. Solo en el caso de La Sexta se ha podido observar que emitió declaraciones distintas del autor de violencia machista en tres ocasiones, utilizando recursos propios para conseguirlas.

No obstante, en todos los casos y en todas las cadenas analizadas, la aparición de estos testimonios siempre ocurría en las noticias denominadas complementarias. Solo se escucha una declaración del agresor ya que este recurso se suele extraer de la respuesta al juez durante la grabación del juicio, y no se trata de declaraciones hechas a cámara. Incluso en las escasas grabaciones de los juicios, se respeta la presunción de inocencia del agresor y se le graba de espaldas. 
Tabla 4. Uso de declaraciones del agresor

\begin{tabular}{|l|c|c|c|c|c|c|}
\hline \multirow{2}{*}{} & \multirow{2}{*}{ TOTAL (\%) } & \multicolumn{5}{|c|}{ CADENAS } \\
\cline { 3 - 7 } & & TV1 & A3 & Cuatro & T5 & La Sexta \\
\hline Una & 3,2 & & & 4,6 & 4,5 & 10,3 \\
\hline Sin declaración & 96,8 & 100,0 & 100,0 & 95,4 & 95,5 & 89,7 \\
\hline
\end{tabular}

Matriz de resultados del análisis de los informativos

Fuente: Elaboración propia

\subsection{Consecuencias penales de las acciones del agresor}

Las consecuencias penales de la violencia machista también están ausentes en el relato audiovisual de los informativos. Solo se mencionaron en el 30\% de las ocasiones, tal y como se muestra en la Tabla 5, donde se puede apreciar que la cadena Cuatro fue la que más veces informó del castigo para los asesinos (46,2\%), frente a Antena 3 que no lo hizo en ningún caso.

Tabla 5. Consecuencias penales de la violencia machista

\begin{tabular}{|l|c|c|c|c|c|c|}
\hline \multirow{2}{*}{} & \multirow{2}{*}{ TOTAL (\%) } & \multicolumn{5}{|c|}{ CADENAS } \\
\cline { 3 - 7 } & & TV1 & A3 & Cuatro & T5 & La Sexta \\
\hline Sí & 30,8 & 28,6 & & 46,2 & 25,0 & 33,3 \\
\hline No & 69,2 & 71,4 & 100,0 & 53,8 & 75,0 & 66,7 \\
\hline
\end{tabular}

Matriz de resultados del análisis de los informativos

Fuente: Elaboración propia

Así pues, parece que en la narración de la detención, el periodista no suele publicar ninguna estadística del número de hombres detenidos o encarcelados por violencia de género, o la cantidad de sentencias dictadas en el último año, o la media de años de cárcel que supone una condena por violencia machista. Aunque el agresor sea el protagonista de la noticia con su detención, las cadenas no suelen incluir una sola imagen que le muestre sino que se emplean recursos audiovisuales donde se vuelve a victimizar a la mujer, más que culpabilizar al agresor. En este sentido, cabe añadir que ninguna cadena de televisión objeto de estudio incluyó en sus noticias sobre violencia machista un solo dato sobre recuento de sentencias condenatorias.

Este dato refleja que entre los procedimientos rutinarios de las redacciones de informativos no está el de tratar de averiguar las consecuencias penales de los agresores, reduciendo el relato sobre la violencia de género a un suceso puntual 
donde hay un agresor, una víctima y un fatal desenlace, sin más explicación social. Cuando existe la oportunidad de hablar del verdadero causante de la violencia de género, se hace casi siempre en una noticia complementaria (de menor duración que la principal y situada en un lugar menos destacado del informativo) y sin citar cuáles son los castigos y los castigados por provocar tan terribles muertes.

Ante esta situación, los discursos de los encuestados varían. Desde los medios de comunicación se justifica esta consideración desigual en la carencia de datos e imágenes centrados en el agresor y en las consecuencias penales de sus actos: "Me parece fundamental que nos lo pongan fácil para poder acceder a esos datos o a esas imágenes” (Periodista 2). Desde el poder judicial se anima a los medios de comunicación a insistir en las medidas punitivas para el agresor, bien a través de la imagen o del lenguaje: "La imagen del culpable entrando en el coche de policía sería muy efectiva. De todos modos, advierto que los medios de comunicación no hacen un seguimiento completo de los casos porque solo vienen el primer día del juicio y muchas veces, ni eso. Nunca hay cámaras cuando se lee el veredicto” (Funcionario 1); “Sí. Yo creo que hay que contar qué consecuencias penales tiene el hecho delictivo" (Funcionario 3).

\subsection{Justificación de las acciones del agresor}

Frente a la ausencia de imágenes y datos que pongan el acento en el agresor y su castigo, sí se han encontrado alguna justificación a sus acciones, tal y como refleja la Tabla 6:

Tabla 6. Justificación de la acción del agresor

\begin{tabular}{|c|c|c|c|c|c|c|}
\hline \multirow{2}{*}{} & \multirow{2}{*}{ TOTAL \% } & \multicolumn{5}{|c|}{ CADENAS } \\
\cline { 3 - 7 } & & TV1 & A3 & Cuatro & T5 & La Sexta \\
\hline Sí & 4,6 & & 33,3 & 7,7 & & 4,6 \\
\hline No & 95,4 & 100,0 & 66,7 & 92,3 & 100,0 & 95,4 \\
\hline
\end{tabular}

Matriz de resultados del análisis de los informativos

Fuente: Elaboración propia

La tendencia general de los informativos $(95,4 \%)$ es la de no servir de altavoz para las excusas del agresor, aunque Antena 3 las comentó en un 33,3\% de las ocasiones, Cuatro lo hizo en un 7,7\%, y La Sexta, en un 4,6\%. A continuación citamos la información publicada el 29 de octubre en Cuatro, referida al juicio de un hombre que mató a su pareja un año antes: "La fiscalía pide 33 años de cárcel para un hombre que prendió fuego a su casa con su mujer dentro. La mató a cuchilladas después de darle un golpe en la cabeza y quemó la vivienda para ocultar el crimen. En el juicio admitió su culpa. Dijo que había sido un arrebato porque estaba muy enojado, ya que ella quería separarse, pero, según 
la fiscalía, lo planeó todo al detalle: compró la gasolina para rociar la vivienda y eligió un día en el que los niños estaban fuera".

Otro ejemplo lo encontramos en un informativo del 26 de marzo, en Antena 3, en el que se narra el juicio por la muerte de una mujer a manos de su pareja: "Y en Málaga ha comenzado el juicio contra un anciano de 84 años que mató a su esposa, también octogenaria. La mujer sufría Párkinson y recibió varias puñaladas una semana antes de que ambos fueran trasladados a una residencia de ancianos. El marido aseguró que lo hizo por compasión. Hoy ha cambiado su versión y ante el jurado ha declarado que habían pactado suicidarse y que fue ella quien lo hizo".

En ambos casos, se incluyen los gravantes que manifiestan los agresores, pero no la posible pena que se impone a este tipo de delitos. Entre aquellos agresores que, o bien se entregaron a la policía tras cometer el crimen, o bien fueron detenidos poco después, el esquema se repite en un gran número de casos con el agresor justificando sus actos y tratando de eximir atenuantes como la ingesta de alcohol, el consumo de drogas o un desequilibrio mental repentino, según los expertos entrevistados en esta investigación. "No son trastornados, son personas normales incapaces de admitir ciertos principios como que tu ex pueda tener otra pareja o que si tu mujer trabaja fuera de casa no se está ligando a los compañeros. Eso no son psicopatías sino problemas de educación" (Funcionario 2); "En la declaración ante la policía hay dos datos que siempre se dan: el 'no recuerdo' y el 'he bebido mucho o he consumido droga'. Pero no aportan ninguna justificación” (Funcionariol); "Se buscan justificaciones como que la víctima no cumplía con el rol que se esperaba de ella (...) porque no le tenía preparada la comida, salía sin hora de regreso, no daba cuenta del dinero que gastaba, etc” (Experto en violencia de género).

En el primer ejemplo citado, el del hombre que prendió fuego a su vivienda con su mujer dentro, se ilustra la noticia con imágenes de la vivienda donde murió la víctima y de su propio cuerpo, algo que se considera morboso, amarillista y redundante en la victimización de la mujer, según la mayoría de los expertos: La criminalización no debería estar reñida con derechos que hay que salvaguardar. Hay que determinar el límite entre la criminalización y la exposición pública y dónde acaba el derecho al honor y la intimidad de las personas" (Funcionario3).

Desde las direcciones de los canales, se reclama la ayuda institucional para hacer más visible al agresor: "Habría que ver las circunstancias en las que se producen las imágenes, pero es probablemente que sí las usaríamos. Me imagino que la policía tendría que analizar el tema de la presunción de inocencia y la difusión de datos, pero yo entiendo que podría hacerse, sí” (Periodista 2); “

\subsection{La influencia de las imágenes en el potencial agresor}

Los directivos de los informativos de las cadenas de televisión entrevistados aceptan que la televisión genera patrones de comportamiento y modos de vida que la población tiende a imitar, pero muestran sus dudas sobre la posibilidad de que 
las noticias sobre violencia de género empujen a un potencial maltratador a 'pasar a la acción', aunque no se manifiestan rotundos en rechazar tal relación.

"Si tuviéramos claro que es así, cambiábamos de la noche a la mañana ese tipo de noticias pero (...) aquí lo hemos debatido y no hay unanimidad en el diagnóstico. Al final lo que más empuja al agresor son cuestiones de su entorno, como que la mujer de repente ha decidido que no vuelve a casa" (Periodista 2); "No lo tengo muy claro, no tiene una base científica que es adonde tendríamos que llegar. Se requiere un estudio profundo al respecto” (Periodista 1); “Como en el suicidio, son temas que se mueven en el límite de los sentimientos y la conducta humana, y de alguna manera plantea el dilema del posible efecto contagio. Yo creo que la televisión no hace que te conviertas en un agresor aunque puede existir el detonante en una situación explosiva" (Periodista 3).

Los funcionarios también manifiestan dudas sobre la influencia de los medios de comunicación en potenciales agresores aunque se inclinan a pensar que dicha relación no es determinante. "Yo creo que los potenciales agresores no son tontos y deben saber lo que puede ir detrás de un hecho delictivo como el que están viendo en la televisión” (Funcionario 1); "Es una pregunta que yo me hago pero creo que no. Otra cosa es que se utilice como amenaza para generar miedo a la víctima. Así como en un suicida está claro, en alguien que no haya pensado convertirse en un asesino lo decida porque lo ha visto en televisión, no creo" (Funcionario 2).

Por su parte, el experto en violencia de género es el más rotundo al respecto. Estima que los patrones de belleza y socialización impactan mucho en la sociedad y son especialmente negativos para las mujeres, pero concluye que los datos sobre la frecuencia en el tiempo de muertes por violencia machista no permite sacar la conclusión de que se está produciendo un efecto contagio. "No podemos hablar de efecto repetitivo. Sí podemos decir que aquel que ya ha llegado a la decisión de acabar con la vida de su pareja puede imitar algunos métodos que haya oído anteriormente (...) Pero la decisión es suya y la toma con independencia de que otro hombre lo haya hecho antes" (Experto en violencia de género).

Por último, los responsables de los espacios informativos de la televisión en nuestro país también se manifiestan en contra de silenciar las noticias sobre violencia machista y, mucho más, en contra de que se imponga como una norma, como ocurre con la mayoría de los casos de suicidio. "Es que empiezas a silenciar esto por motivos sociales y terminas silenciando cualquier cosa por motivos sociales (...) No podemos decidir que nos callamos esto porque está pasando y nosotros contamos las cosas que ocurren (...) el riesgo es tan alto y la correspondencia (con un supuesto efecto contagio) es tan difusa, que me parece mayor riesgo no contarlo" (Periodista 2); "Yo fui de las más activas en oponerme al silencio que nos proponía la administración (...) La libertad de información tiene que estar por encima y sobre todo (...) no se puede desaprovechar nuestro papel de denuncia y de formación de opiniones" (Periodista 1). 


\section{Discusión}

El estudio y seguimiento del perfil del sujeto maltratador ocupa un gran número de publicaciones tanto del ámbito de la psicología, como de la psiquiatría y la criminalística. Cualquiera que sea la aproximación científica a esta realidad, la única evidencia detrás de cada acto de violencia machista es que hay un único responsable del delito: el agresor.

Apenas han transcurrido diez meses de 2016 y ya se contabilizan 33 mujeres fallecidas a manos de sus parejas o exparejas. Según datos del Ministerio de Sanidad, Servicios Sociales e Igualdad, el primer trimestre de este año sería uno de los más sangrientos en los últimos diez años (http://www.violenciagenero.msssi.gob.es/violenciaEnCifras/victimasMortales/fichaMujeres/pdf/VMortales_2016_15_03.pdf Consultado 4 abril 2016).

Esta realidad, que lejos de desaparecer parece seguir dejando malheridas o muertas cada vez a un mayor número de mujeres, requiere también de la implicación y participación de los medios de comunicación, sobre todo, de la televisión, en tanto en cuanto, es el medio por el que la mayoría de los españoles se continúa informando.

Entre la inmensa cantidad de acontecimientos que ocurren en el día a día, los medios de comunicación seleccionan en cada momento qué será noticia y quiénes serán los protagonistas de esas noticias, estableciendo en las agendas de los públicos aquellos temas que deben ser percibidos como importantes para la población. Las voces recogidas en este trabajo ponen de manifiesto que el problema de la violencia machista debería estar presente en esas agendas, como una fórmula para ayudar a evitar más muertes.

Ahora bien. Como se ha presentado en este artículo, no se trata solamente de que los medios aborden el tema sino que se refuerce la culpabilidad del agresor en el discurso informativo. En un gran número de ocasiones, la figura del agresor, que ha quemado viva, acuchillado, apaleado o atropellado mortalmente a la víctima, pasa casi inadvertida en el discurso informativo. Incluso, en ocasiones, se incluyen argumentos que justifican su conducta, si bien la tendencia general percibida en el estudio es la de no servir de altavoz para las excusas del agresor.

Entre los expertos entrevistados, se anima e insiste a los medios de comunicación para que den a conocer en sus mensajes las medidas punitivas para el agresor. La imagen del agresor contribuye a enviar un mensaje de causa-efecto necesario para que la sociedad comprenda que estos crímenes no quedan impunes y tienen rostro, no son una entelequia.

No obstante, es una obligación legal el cuidado de dichas imágenes para preservar la presunción de inocencia y el derecho al honor del detenido, pero el discurso informativo debe incluir claramente las consecuencias legales y penales de los actos cometidos. Si bien no se mostraría al autor de violencia machista hasta que no hubiese una sentencia condenatoria, crece la opinión entre los profesionales entrevistados de que el agresor ha de ser identificado claramente, con las precauciones que impone siempre la presunción de inocencia. 


\section{Referencias bibliográficas}

Álvarez-Dardet, S. M., Pérez Padilla, J. y Lorence Lara, B. (2013): "La violencia de pareja contra la mujer en España: cuantificación y caracterización del problema, las víctimas, los agresores y el contexto social y profesional”, Psychosocial Intervention, n. 22 (1), pp. 41-53. [Disponible en: http://scielo.isciii.es/pdf/inter/v22n1/06.pdf]

Bandrés Goldáraz, E. (2011): "Propuesta para el tratamiento eficaz de la violencia de género", Revista Científica de Información y Comunicación, n. 8, pp. 111-136.

Campbell, J. C., Webster, D., Koziol-McLain, J., Block, C., Campbell, DW., Curry, MA., Gary F., McFarlane, JM., Sachs, C., Sharps, P., Ulrich, Y., Wilt, S. A. (2003): "Assessing risk factors for intimate partner homicide. National Institut of Justice Journal", n. 250, pp. 14-19. [Disponible en: https://www.ncjrs.gov/pdffiles1/jr000250e.pdf]

Comas, D. (2015): "News of partner femicides: the shift from private issue to public problem", European Journal of Communication, n. 30 (2), pp. 121-136.

Conger, J. J. y Miller, W. C. (1966): Personality, Social class and delinquency. Nueva York: Wiley.

Consejo General del Poder Judicial (2012): Análisis de las sentencias dictadas por los tribunales del jurado y por las Audiencias Provinciales en el año 2010, relativas a homicidios y/o asesinatos consumados entre los miembros de la pareja o expareja, Madrid. [Disponible en: http://www.poderjudicial.es/cgpj/es/Temas/Violencia_domestica_y_de_genero/Grupos_de_expertos/Analisis_de_las_sentencias_dictadas_por_los_Tribunales_del_Jurado_y_por_las_Audiencias_Provinciales_en_el_ano _2010_relativas_a_homicidios_y_o_asesinatos_consumados_entre_los_miembros_de_la_pareja_o_ex_pareja]

Defensor del Pueblo (1998): Informe sobre la violencia contra las mujeres, Madrid. [Disponible en: http://www.defensordelpueblo.es/es/Documentacion/Publicaciones/monografico/Documentacion/Estudiomujeres.pdf]

Delegación del Gobierno contra la violencia sobre la mujer (2006): Plan Nacional de Sensibilización y prevención de la Violencia de Género. Madrid.

Dubugras, S. y Guevara, B. (2007): "Homicidio seguido de suicidio", Universitas Psychological, n. 6 (2), pp. 231-244.

Espada, F. J. y P. Torres (1996): Violencia en casa. Madrid: Aguilar.

Expósito, F. y Ruíz, S. (2009): “Tratamiento para maltratadores: Una propuesta de intervención desde la perspectiva de género", en F. Fariña, R. Arce y G. Buela-Casal (eds.): Violencia de género. Tratado psicológico y legal. Madrid: Biblioteca Nueva, pp. 221-233.

Fernández Arribas, J. y Noblejas, M. (2010): Cómo informar sobre violencia contra la mujer en las relaciones de pareja. Madrid: Centro Reina Sofía. [Disponible en: http://igualdade.xunta.gal/sites/default/files/files/documentos/como_informar_ violencia_parella.pdf]

Fernández Teruelo, J. (2011): "Evolución real del fenómeno, el suicidio del agresor y la incidencia del tratamiento mediático", Revista Española de Investigación Criminológica, n. 9, pp. 10-14. 
Ferrer, V. A. y Bosch, E. (2005): "Características de los hombres violentos en el hogar: estudio de una muestra española a partir de los informes de sus parejas”, Anuario de Psicología, n. 36, pp. 159-179.

Gallego, J. (2003): “De las recomendaciones a los mecanismos. Producción informativa y su incidencia en el tratamiento de la violencia de género", en M. Ramírez Alvarado (ed.): Medios de comunicación y violencia contra las mujeres, Sevilla: Instituto Andaluz de la Mujer, pp. 227-236.

García Galera, M. C. y Berganza Conde, M. R. (2005): "El método científico aplicado a la investigación en comunicación mediática”, en Berganza y Ruiz (coords.): Investigar en Comunicación, Madrid: McGraw-Hill.

Herrera Enríquez, M. C. y Expósito Jiménez, F. (2009): "Responsabilidad compartida: Influencia de los Medios de Comunicación en la atribución de culpabilidad y justificación de la violencia de género", Anuario de Psicología Jurídica, n. 19, pp. 103-110. [Disponible en: http://www.redalyc.org/pdf/3150/315025340009.pdf]

Ley 1/1982, de 5 de mayo, de protección civil, derecho al honor, a la intimidad personal y familiar y a la propia imagen, 115 Boletín Oficial del Estado, Capítulo I (1982). [Disponible en: https://www.boe.es/boe/dias/1982/05/14/pdfs/A1254612548.pdf]

López García, E. (2004): “La figura del agresor en la violencia de género: características personales e intervención”, Papeles del Psicólogo, n. 88. [Disponible en: http://www.papelesdelpsicologo.es/ vernumero.asp?id=1160]

Montero Gómez, A. (14/09/2006): “El suicidio machista”, Diario El Correo. [Disponible en: http://www.mujeresenred.net/ spip.php?article700]

Radio Televisión Española (2010): Manual de estilo. Tratamiento de la violencia contra las mujeres. Madrid. [Disponible en: http://manualdeestilo.rtve.es/cuestiones-sensibles/5-5-tratamiento-de-la-violencia-contra-las-mujeres/]

Varona, D. y Gabarrón, N. (2015): "El tratamiento mediático de la violencia de género en España (2000- 2012): agenda setting y agenda building”, InDret Revista para el Análisis del Derecho. [Disponible en: http://www.indret.com/pdf/1123.pdf]

Vives-Cases, C., Torrubiano, J., y Álvarez-Dardet, C. (2009): “The effect of televisión news items on intimate partner violence murder", The European Journal of Public Health, n. 19 (6), pp. 592-596. 